\title{
Tranexamic Acid Pre-Operative Prophylaxis To Reduce Bleeding During Femoral Interlocked Intramedullary Nailing: A Randomized Control Study
}

\author{
Almar S. Bantolo, M.D' Kutch V. Yasa, M.D, Lucille P. Detoyato, MD, FPOA \\ Western Visayas Medical Center \\ Department of Orthopedics \\ DOI: 10.29322/IJSRP.10.10.2020.p10617 \\ http://dx.doi.org/10.29322/IJSRP.10.10.2020.p10617
}

\begin{abstract}
Objectives: To evaluate the efficacy of intravenous Tranexamic Acid as pre-operative prophylactic management for patients undergoing Open Reduction Internal Fixation (ORIF) Interlocked Intramedullary Nailing of the Femur in minimizing intra-operative bleeding at Level III trauma Center in a tertiary government hospital.

Methods: Patients were admitted under the Department of Orthopedics Level III trauma Center in a tertiary government hospital. Baseline hemoglobin and hematocrit was taken upon admission along with x-ray of the femur. Laboratories upon admission served as baseline prior to the operation. A repeat hemoglobin and hematocrit were done prior to the scheduled surgery if the patient has delayed surgery for more than two weeks. Single blind sampling was used. All the patients in the study underwent ORIF IM Nailing of the femur. Patients in the Tranexamic group was given tranexamic acid $1 \mathrm{gm}$ after induction of anesthesia. Postoperative estimated total blood loss was recorded and postoperative hemoglobin and hematocrit levels were determined. The control group that was included in the study underwent ORIF IM Nailing of the Femur but were not given Tranexamic Acid. Postoperative estimated total blood loss was recorded and postoperative hemoglobin and hematocrit levels were determined. Estimated blood loss was determined from anesthesia records.

Results: In our study, 17 patients were given TXA while 14 patients served as the control group and did not receive TXA. During surgery, there was a note of minimal bleeding especially upon skin incision and muscle splitting compared to those patients without TXA. Results also showed that there were significant differences in the drop in hemoglobin and hematocrit levels and in the estimated blood loss compared to the control group. During this study, we also note that the rate of blood transfusion were minimized on the TXA group compared to the non- TXA group.

Conclusion The results of the study showed that there is a significant difference in the drop in the hemoglobin and hematocrit level between the patients who received tranexamic acid and those who did not receive tranexamic acid. Furthermore, there is also a significant difference in the estimated blood loss between the two groups. This showed that tranexamic acid is an effective prophylactic drug that reduces bleeding among patients with femoral shaft fracture undergoing open reduction interlocked intramedullary nailing.
\end{abstract}

Keywords: Tranexamic Acid, Hemoglobin, Hematocrit, Estimated Blood Loss, Interlocked IM Nailing Femur.

\section{INTRODUCTION}

The Province of Iloilo, home to 1.81 million people, records nearly 5,000 road crash incidents in the first half of 2017. According to the 2014 data from the Philippine Statistics Authority, 733 people died from road crash accidents in Region VI. If population is taken into account, Western Visayas is the most affected region in the Islands of Visayas in terms of road crash deaths (Francisco, 2017).

Through the years, treatment methods involving fractures evolved from non-operative to operative management. Intramedullary nailing has become the gold standard for operative treatment of femoral diaphyseal fractures (Brumback, et al, 2006). 
Open reduction intramedullary nailing of the femur is extensive and blood is usually needed to undergo the procedure. However, due to scarcity and difficulty in securing blood, it is considered one of the reasons for the delay in surgery.

Tranexamic acid (TXA) is an antifibrinolytic drug that has been shown by several studies to be effective in reducing blood loss and blood transfusions after orthopaedic surgeries (Amer KM, Rehman, Amer K and Haydel,2018; Dai, Zhou, Zhang, H., and Zhang, J., 2018; Gausden, et al., 2017; Goldstein, Feldmann, Wulf, and Wiesmann, 2017; Lin, and Woolf, 2016; Sridharan, and Sivaramakrishnan, 2018; Vijay, Bedi, Mitra, and Das, 2013). Several studies have reported the role and efficacy of TXA in hip and knee replacement surgery. However, the effectiveness of TXA use in orthopaedic fracture surgeries specifically in femoral shaft fractures still remains unclear. The purpose of this study is to investigate the effectiveness and safety of TXA treatment in reducing blood loss in patients who underwent open intramedullary nailing surgeries for femoral shaft fractures.

General Objective

To evaluate the efficacy of intravenous Tranexamic Acid as pre-operative prophylactic management for patients undergoing Open Reduction Internal Fixation (ORIF) Interlocked Intramedullary Nailing of the Femur in minimizing intraoperative bleeding at Level III trauma Center in a tertiary government hospital.

\section{Specific Objective}

1. To describe the demographic profile of patients given intravenous Tranexamic Acid as pre-operative prophylactic management for patients undergoing Open Reduction Internal Fixation (ORIF) Interlocked Intramedullary Nailing of the Femur as to:
A. Age
B. Sex

2. To determine the efficacy of Tranexamic Acid as pre-operative prophylactic management for patients undergoing Open Reduction Internal Fixation (ORIF) Interlocked Intramedullary Nailing of the Femur as to:
A. Estimated Blood Loss
B. Drop in Hemoglobin Level
C. Drop in Hematocrit Level

\section{RESEARCH AND COLLECT IDEA}

This study was designed to evaluate the efficacy of intravenous Tranexamic Acid as pre-operative prophylactic management for patients undergoing Open Reduction Internal Fixation (ORIF) Interlocked Intramedullary Nailing of the Femur in minimizing intra-operative bleeding at a Level III trauma Center in a tertiary government hospital.

\section{Research Design \\ A randomized control study design was employed in the study.} Study Setting

This study was done at Level III trauma Center in a tertiary government hospital.

\section{Duration of the Study}

This study was conducted from January 2018 to June 2019.

\section{Participants/Subject/Respondents}

All patients admitted with fracture of the middle shaft of the femur classified according to AO who underwent ORIF Interlocked Intramedullary Nailing.

\section{Inclusion Criteria}

1.) age 20-70 years old

2.) have simple fracture at the middle $3^{\text {rd }}$ of femoral shaft classified in $\mathrm{AO}$ as $\mathrm{AO} 32-\mathrm{A}$ 


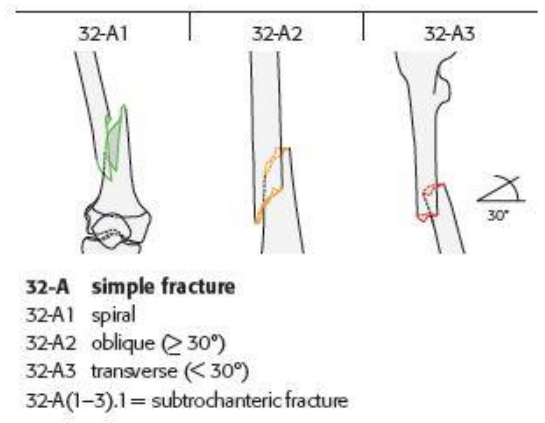

(Source: AO Trauma)

3.) injury resulted from motor vehicular accident.

\section{Exclusion Criteria}

1.) patients with multiple injuries including femoral shaft

2.) patients with co-morbid conditions and bleeding disorders

\section{Procedure of the study}

Patients were admitted under the Department of Orthopedics Level III trauma Center in a tertiary government hospital and have fractures of the middle $3^{\text {rd }}$ of the femur classified according to AO specifically AO 32-A underwent Open Reduction Internal Fixation (ORIF) Interlocked Intramedullary (IM) Nailing. All participants were oriented, apprised and an informed consent was secured prior to the study.

Baseline hemoglobin and hematocrit was taken upon admission along with x-ray of the femur. Laboratories upon admission served as baseline prior to the operation. A repeat hemoglobin and hematocrit was done prior to the scheduled surgery if the patient has delayed surgery for more than two weeks. Single blind sampling was used.

All the patients in the study underwent ORIF IM Nailing of the femur. Patients in the Tranexamic group was given tranexamic acid $1 \mathrm{gm}$ after induction of anesthesia. Postoperative estimated total blood loss was recorded and postoperative hemoglobin and hematocrit levels were determined.

The control group that was included in the study underwent ORIF IM Nailing of the Femur but were not given Tranexamic Acid. Postoperative estimated total blood loss was recorded and postoperative hemoglobin and hematocrit levels were determined. Estimated blood loss was determined from anesthesia records.

\section{Data Analysis Procedure}

The results of the study were analyzed using Statistical Package for Social Sciences (SPSS) version 19. Independent T-test was used to analyze the data.

\section{RESULTS AND FINDINGS}

From January 2018 to June 2019, 50 patients were randomized in the study of which 19 were excluded because of existing co-morbidities. Data from thirty one patients were analyzed after randomization, 17 patients were given TXA and 14 patients were not given TXA. The study population consist of 22 males and 9 females, with the mean age of 64 .

Table 1. Demographics

Sex

\begin{tabular}{|l|l|l|}
\hline & Frequency & Percent \\
\hline Male & 22 & 4.2 \\
\hline Female & 9 & 1.7 \\
\hline Total & 31 & 100 \\
\hline
\end{tabular}




\section{Age}

\begin{tabular}{|c|c|c|}
\hline & Frequency & Percent \\
\hline 20 & 6 & 1.1 \\
\hline 21 & 1 & .2 \\
\hline 22 & 1 & .2 \\
\hline 24 & 3 & .6 \\
\hline 25 & 2 & .4 \\
\hline 26 & 1 & .2 \\
\hline 27 & 1 & .2 \\
\hline 28 & 2 & .4 \\
\hline 29 & 1 & .2 \\
\hline 33 & 1 & .2 \\
\hline 34 & 1 & .2 \\
\hline 35 & 1 & .2 \\
\hline 36 & 1 & .2 \\
\hline 37 & 1 & .2 \\
\hline 39 & 1 & .2 \\
\hline 45 & 1 & .2 \\
\hline 51 & 1 & .2 \\
\hline 57 & 1 & .2 \\
\hline 59 & 2 & .4 \\
\hline 60 & 1 & .2 \\
\hline 64 & 1 & .2 \\
\hline Total & 31 & 100 \\
\hline
\end{tabular}


Patient Distribution

\begin{tabular}{|l|c|c|}
\hline & \multicolumn{2}{|c|}{ Percent } \\
\hline with TXA & 17 & 3.2 \\
\hline with out TXA & 14 & 2.7 \\
\hline Total & 31 & 100 \\
\hline
\end{tabular}

In the study groups, baseline hemoglobin ( $\mathrm{Hgb})$ and hematocrit $(\mathrm{Hct})$ were requested upon admission prior to surgery. If there was a delay of surgery, baseline hemoglobin recorded is the repeat hemoglobin prior to the surgery.

Table 2. Baseline Hemoglobin

\begin{tabular}{|c|c|c|}
\hline & Frequency & Percent \\
\hline 11.00 & 1 & .2 \\
\hline 11.50 & 2 & .4 \\
\hline 12.00 & 3 & .6 \\
\hline 12.30 & 2 & .4 \\
\hline 12.50 & 2 & .4 \\
\hline 12.60 & 1 & .2 \\
\hline 12.80 & 1 & .2 \\
\hline 13.00 & 4 & .8 \\
\hline 13.20 & 3 & .6 \\
\hline 13.40 & 4 & .8 \\
\hline 13.50 & 1 & .2 \\
\hline 13.60 & 2 & .4 \\
\hline 13.70 & 2 & .4 \\
\hline 14.10 & 2 & .4 \\
\hline 14.90 & 1 & .2 \\
\hline Total & 31 & 5.9 \\
\hline Total & 527 & 100.0 \\
\hline
\end{tabular}


Table 3. Baseline hematocrit

\begin{tabular}{|c|c|c|}
\hline & Frequency & Percent \\
\hline .31 & 1 & .2 \\
\hline .35 & 5 & .2 \\
\hline .36 & 1 & .8 \\
\hline .37 & 4 & .8 \\
\hline .38 & 4 & .9 \\
\hline .39 & 5 & 1.1 \\
\hline .40 & 6 & .4 \\
\hline .41 & 2 & .4 \\
\hline .42 & 2 & .2 \\
\hline .44 & 1 & 5.9 \\
\hline Total & 31 & 100.0 \\
\hline Total & 527 & \\
\hline
\end{tabular}

Drop in Hemoglobin Level

Baseline hemoglobin levels were noted in each study group. Drop of hemoglobin levels were compared between the two study groups. This study showed that there is a significant difference between the change in hemoglobin levels between patients who received tranexamic acid and the non TXA group. This showed that the TXA group had lower blood loss $(M=$ $1.42, S D=0.63)$ than the non-TXA group $(M=2.01, S D=0.97), t(29)=2.05, p=0.05$.

Table 4: Drop in the hemoglobin level of both the TXA and non-TXA groups.

\begin{tabular}{|l|l|l|l|l|l|l|l|}
\hline Group & $\mathrm{N}$ & Mean & SD & Df & T & P & Interpretation \\
\hline $\begin{array}{l}\text { TXA } \\
\text { Group }\end{array}$ & 17 & 1.42 & 0.63 & 29 & 2.05 & 0.05 & Sig \\
\hline $\begin{array}{l}\text { Non- } \\
\text { TXA } \\
\text { Group }\end{array}$ & 14 & 2.01 & 0.97 & & & & \\
\hline
\end{tabular}

*significant at $\alpha=.05$

Drop in Hematocrit Level

Baseline hematocrit levels were noted in each study group. Drop of hematocrit levels were compared between the two study groups. The results showed that there is a significant difference between the change in hematocrit levels between the TXA group and the non-TXA group. This shows that the TXA group had lower blood loss $(M=0.024, S D=0.012)$ than the non-TXA group $(M=0.051, S D=0.027), t(29)=3.75, p=0.001$.

Table 5: Drop in the Hematocrit Level of both the TXA and non-TXA groups

\begin{tabular}{|l|l|l|l|l|l|l|l|}
\hline Group & N & Mean & SD & df & T & P & Interpretation \\
\hline $\begin{array}{l}\text { TXA } \\
\text { group }\end{array}$ & 17 & 0.024 & 0.012 & 29 & 3.75 & 0.001 & sig \\
\hline $\begin{array}{l}\text { Non- } \\
\text { TXA } \\
\text { group }\end{array}$ & 14 & 0.051 & 0.027 & & & & \\
\hline
\end{tabular}

*significant at $\alpha=.05$ 
Estimated Blood Loss

Estimated blood loss was calculated based on the anesthesia record which included suction drain, and sponge count after surgery. Results showed that there is a significant difference between the estimated blood loss between TXA group and the non-TXA group. This shows that the TXA group had lower blood loss $(M=394.12, S D=42.87)$ than the non -TXA group $(M=478.57, S D=108.69, t(29)=2.95, p=0.006$.

Table 6. Estimated blood loss of both the TXA and non-TXA groups

\begin{tabular}{|l|l|l|l|l|l|l|l|}
\hline Group & $\mathrm{N}$ & Mean & SD & df & T & P & Interpretation \\
\hline $\begin{array}{l}\text { TXA } \\
\text { group }\end{array}$ & 17 & 394.12 & 42.87 & 29 & 2.95 & 0.006 & sig \\
\hline $\begin{array}{l}\text { Non- } \\
\text { TXA } \\
\text { group }\end{array}$ & 14 & 478.57 & 108.69 & & & & \\
\hline
\end{tabular}

*significant at $\alpha=.05$

\section{Discussion}

Tranexamic acid is a synthetic antifibrinolytic drug used to prevent bleeding. There are three methods of administering TXA to reduce blood loss; intramuscular, oral and intravenous. In one study by Benoni and Fredin, (1996) tranexamic acid reduced the number of patients receiving blood transfusion and the number of blood units transfused to one third compared to those who underwent surgery without TXA.

In our institution, femoral fracture is one of the most commonly managed long bone fractures. Prior to surgery, blood is prepared and the difficulty in securing them has been one of the reasons for the delay in surgery= The present study was conducted in our institution in order to evaluate if TXA is helpful in minimizing bleeding during surgery. Although several studies have been conducted in the use of TXA in total knee arthroplasty and hip arthroplasty, this study was formulated to determine if TXA is also applicable in other femoral fracture surgery especially in performing Interlocked Intramedullary Nailing.

Yi, et al, (2016) used intravenous combined with topical administration of TXA in patients undergoing a primary unilateral total hip arthroplasty and showed that it significantly reduced postoperative bleeding and transfusion rate. The results of this study also showed that IV TXA significantly decreased blood loss compared to those patients who were not given with TXA. This is shown by the significant difference in the drop in hemoglobin and hematocrit levels between the two groups.

In our study, 17 patients were given TXA while 14 patients served as the control group and did not receive TXA. During surgery, there was a note of minimal bleeding especially upon skin incision and muscle splitting compared to those patients without TXA. Results also showed that there were significant differences in the drop in hemoglobin and hematocrit levels and in the estimated blood loss compared to the control group. During this study, we also note that the rate of blood transfusion were minimized on the TXA group compared to the non- TXA group.

In a meta-analysis study by Dai et al, (2018) on the effectivity of tranexamic acid for reducing bleeding and transfusions in primary total knee arthroplasty, it revealed that TXA is safe and effective and no note of adverse effects were mentioned during the procedure.

Vijayet al (2016) reported in their study that TXA significantly reduces postoperative blood loss and transfusion requirements during major hip and femoral surgeries.

\section{CONCLUSION}

The results of the study showed that there is a significant difference in the drop in the hemoglobin and hematocrit level between the patients who received tranexamic acid and those who did not receive tranexamic acid. Furthermore, there is also a significant difference in the estimated blood loss between the two groups. This showed that tranexamic acid is an effective prophylactic drug that reduces bleeding among patients with femoral shaft fracture undergoing open reduction interlocked intramedullary nailing.

\section{Recommendation}

For future studies, large sample population size and inclusion of patients with more complicated femoral fractures is recommended to further evaluate the use of TXA for orthopedic surgery specifically femoral shaft fracture. Rate of blood transfusion may also be included as one of the variables in future studies to further determine the effectivity of TXA in reducing blood loss. 


\section{REFERENCES}

1. Brumback, R. J., Uwagie-Ero, S., Lakatos, R. P., Poka, A., Bathon, G. H., \& Burgess, A. R. (2006). Intramedullary nailing of femoral shaft fractures. Part II: Fracture-healing with static interlocking fixation. Orthopedic Trauma Directions, 4(01), 29-33.

2. Court-Brown, C., Heckman, J., Mcqueen, M., Ricci, W. and Tornetta, P III. (Eds). (2015). Rockwood and Green's fractures in adults(Vol. 1). Lippincott Williams \& Wilkins.

3. Dai, W. L., Zhou, A. G., Zhang, H., \& Zhang, J. (2018). Most effective regimen of tranexamic acid for reducing bleeding and transfusions in primary total knee arthroplasty: a meta-analysis of randomized controlled trials. The journal of knee surgery, 31(07), 654-663.

4. Gausden, E. B., Qudsi, R., Boone, M. D., O'Gara, B., Ruzbarsky, J. J., \& Lorich, D. G. (2017). Tranexamic acid in orthopaedic trauma surgery: a meta-analysis. Journal of orthopaedic trauma, 31(10), 513-519.

5. Goldstein, M., Feldmann, C., Wulf, H., \& Wiesmann, T. (2017). Tranexamic acid prophylaxis in hip and knee joint replacement. Deutsches Ärzteblatt International, 114(48), 824.

6. Kuppa, S., Wang, J., Haffner, M., \& Eppinger, R. (2001). Lower extremity injuries and associated injury criteria (No. 2001-06-0160). SAE Technical Paper

7. Lin, Z. X., \& Woolf, S. K. (2016). Safety, efficacy, and cost-effectiveness of tranexamic acid in orthopedic surgery. Orthopedics, 39(2), 119-130.

8. Sridharan, K., \& Sivaramakrishnan, G. (2018). Tranexamic acid in total hip arthroplasty: mixed treatment comparisons of randomized controlled trials and cohort studies. Journal of orthopaedics, 15(1), 81-88.

9. Vijay, B. S., Bedi, V., Mitra, S., \& Das, B. (2013). Role of tranexamic acid in reducing postoperative blood loss and transfusion requirement in patients undergoing hip and femoral surgeries. Saudi journal of anaesthesia, 7(1), 29.

10. Yi, Z., Bin, S., Jing, Y., Zongke, Z., Pengde, K., \& Fuxing, P. (2016). Tranexamic acid administration in primary total hip arthroplasty: a randomized controlled trial of intravenous combined with topical versus single-dose intravenous administration. JBJS, 98(12), 983-991.

11. Zhang, L. K., Ma, J. X., Kuang, M. J., Zhao, J., Lu, B., Wang, Y., ... \& Fan, Z. R. (2017). The efficacy of tranexamic acid using oral administration in total knee arthroplasty: a systematic review and meta-analysis. Journal of orthopaedic surgery and research, 12(1), 159.

\section{AUTHORS}

First Author - Almar S. Bantolo, MD, Western Visayas Medical Center Department of Orthopedics, abantoloMD@ gmail.com Second Author - Kutch V. Yasa, MD, Western Visayas Medical Center Department of Orthopedics, kuvsa14@gmail.com Third Author - Lucille P. Detoyato, MD, FPOA, Western Visayas Medical Center Department of Orthopedics, lucilmd@gmail.com 